\title{
Plant toxic proteins and their current significance for warfare and medicine
}

\author{
Jiří Patočka ${ }^{1}$ and Ladislav Středa ${ }^{2}$ \\ ${ }^{1}$ Department of Toxicology, Military Medical Academy, Hradec Králové and Faculty of Health and Social \\ Studies, University of South Bohemia, České Budějovice, Czech Republic \\ ${ }^{2}$ Department for Control of the Prohibition of Chemical and Biological Weapons, State Office for Nuclear Safety, \\ Praha, Czech Republic
}

\begin{abstract}
Summary
Abrin, ricin, viscumin, modeccin, and volkensin are very potent toxins derived from plants. They are glycoproteins composed of two polypeptide chains linked by a disulphide bridge. The A-chain is the enzymatic toxic moiety and B-chain is responsible for bonding to the target cell and internalization of toxin. The toxic part of the toxin molecule removes an adenine from a specific adenosine residue in ribosomal RNA and block proteosynthesis. That is the reason of extreme toxicity of these compounds and their capacity to be used as biological warfare agents or terrorist weapon. Therefore all these compounds are in the schedules of controlled biological agents and toxins. Contrariwise, plant ribosome-inactivating proteins are studied intensive as possible chemotherapeutic agents.
\end{abstract}

Keywords: plant toxic proteins - ribosome inactivating proteins - abrin - ricin - modeccin viscumin - volkensin - warfare - medicine

\section{INTRODUCTION}

Many organisms produce potently toxic proteins that act on other cells, sometimes with lethal effects. In this way, such proteins help to increase the chance of survival or proliferation of the producing organism. Some of them have an exquisitely specific action. For example ricin and ricin-like proteins have evolved to selectively target ribosomes within the cells of susceptible organisms, thereby enabling a fatal disruption of protein synthesis. These particular toxins are able to exploit intracellular transport pathways to travel from the cell surface to their substrates in the cytosol. Plant toxic proteins belong to a group of phytotoxins, which inhibit the protein synthesis of eukaryotic cells. The toxins of this group are glycoproteins with molecular weights of about $60 \mathrm{kDa}$ which consist of two subunits linked into a dimer by a disulfide bond. One of the subunits is lectin with sites for carbohydrate binding (B-chain), and the other subunit is specific $\mathrm{N}$ glycosidase (A-chain), which modifies the $28 \mathrm{~S}$ rRNA-60S ribosomal subunit. The group of proteins known as the lectins was first recognised in plant seeds and they bind to specific sugars. Although lectins, in general, are not very toxic, there are some relationships between lectins and toxins (Wang and $\mathrm{Xu}$ 2000). They may also serve as recognition markers in cellular differentiation and act as immunotoxin. Only A-chain is toxic due to inhibiting protein synthesis. The A-chain catalytically inactivates $60 \mathrm{~S}$ ribosomal subunit by removing adenine from positions 4 and 324 of $28 \mathrm{~S}$ rRNA. Ribosome-inactivating proteins (RIP) have been identified in many plants and some of them are very toxic, but only in connection with B-chain. The A-chain is carrier of toxicity, but B-chain binds to cell surface receptors and facilitate a transport of the A-chain across the cell membrane. The A-chain is not active until it is internalized by the cell, where halts protein synthesis. Each toxin molecule can disable approximately 2000 polysomes per minute, enough to eventually kill the cell. The most known plant toxic proteins of this type are ricin, abrin, modeccin, viscumin and volkensin. Likewise act some bacterial protein toxins, for instance diphteria 
toxin or pseudomonas toxin but intimate mechanism of toxic action is not identical. The extreme toxicity of these compounds tempts extremists to warfare or terrorist misuse, their capability to block protein synthesis lure physicians to exploit them as anticancer therapeutics.

Ricin, abrin, modeccin, viscumin, and volkensin are natural toxic compounds registered as highly risk toxins controlled under Decree No. 474/2002 Coll. implementing the Act No. 281/2002 Coll., on some measures concerning bacteriological (biological) and toxin weapons prohibition and Decree No. 298/2001 Coll. implementing the Act No. 21/1997 Coll., on control of exports and imports of goods and technologies subject to international control regimes. Toxins are controlled when they are an isolated live culture of a pathogen agent, or a preparation of a toxin agent, which has been isolated or extracted from any source, or material including living material which has been deliberately inoculated or contaminated with the agent. Isolated live cultures of a pathogen agent include live cultures in dormant form or in dried preparations, whether the agent is natural, enhanced or modified. An agent is covered by these legislative norms except when it is in the form of a vaccine or in the solution with the concentration below $1 \%$. A vaccine is a medicinal product in a pharmaceutical formulation licensed by, or having marketing or clinical trial authorisation from, the regulatory authorities of either the country of manufacture or of use, which is intended to stimulate a protective immunological response in humans or animals in order to prevent disease in those to whom or to which it is administered.

\section{MOLECULAR STRUCTURE AND TOXIC ACTION}

Many plants produce Ribosome Inactivating Proteins (RIPs)-enzymes that act on ribosomes in a highly specific way, thereby inhibiting protein synthesis. Some RIPs can bind to and enter cells, making them among the most-toxic substances known so far (Sandvig and Olsnes 1982). The lectins like ricin, abrin, viscumin, volkensin and modeccin come under the group of toxic lectins of A- and B-chains. The A-chain is an enzyme whereas B-chain is a lectin. Most of the research and information on plant toxic proteins has been obtained from studies on ricin. Chemical structure and the mechanism of toxic action all this ricin-related protein family are very similar (Olsnes et al. 1974). The resemblance of A- and B-chains of all RIPs is evident from the fact that they are interchangeable and hybrid toxin built-up from modeccin A-chain and ricin B-chain was prepared (Sundan et al. 1983).
The lectin part of toxin molecule is liable for recognition of cell surface and binding. Having bound diffusely to the cell membrane, the protein is internalized. Part of the toxin bound to the cell surface undergoes receptor-mediated endocytosis (Manske et al. 1989). Uptake of toxic plant proteins is not nearly as fast as the uptake of molecules like transferrin, which use similar mechanisms, and thus there is a dwell between administration of the toxin and development of toxic effects (Endo et al. 1989). In mice, even with injection of extremely large amounts of toxin they do not die earlier than after ten hours. As soon as the toxin molecule is internalized to vacuolar and tubo-vesicular portions of the endosomal system where most of it remains bound to the plasma membrane, protein is transported retrograde through the Golgi to the endoplasmic reticulum and the A-chain to bind to its target ribosome site and cause toxic effects in the cell. Ribosomes are complex structures, composed of protein and nucleic acid (rRNA) components. They are responsible for protein synthesis from mRNA and amino-acid subunits linked to tRNA. Ribosomes have two subunits, a large subunit, which contains an rRNA fragment known as the 60s fragment and a smaller subunit. The 60S fragment is made up of several pieces of RNA, one of which is the $28 \mathrm{~S}$ rRNA. It is thought to be the RNA components that are most important in protein chain elongation catalysis (Larsson et al. 2002). The Achain is an $\mathrm{N}$-glycosidase, which removes bases from nucleic acids. It catalytically and irreversibly inactivates the 60S, large ribosomal subunit (Manske et al. 1989) so that modifies a base in the $28 \mathrm{~S}$ rRNA fragment of the 60S RNA chain and thus halts protein synthesis.

\section{RICIN}

Ricin is a protein produced by the castor oil plant, Ricinus Communis. It is native to tropical Africa, but has naturalised sub-tropical and temperate areas as well. The whole of the plant is poisonous, containing the toxin ricin, which reaches the highest levels in the seeds. The seeds also contain a purgative oil, the triglyceride of ricinoleic acid. The seeds have been used in folk medicine against many diseases for centuries. The oil is used for lubrication in the motor industry, ricin being left in the fibrous plant residue after pressing, and is still used in medicine as a laxative.

Ricin is the compound responsible for toxicity of the seeds of $R$. communis (Rutenber and Robertus 1991). Ricin has been known as a poison for years, usually through livestock deaths. One to three seeds may be fatal to a child; two to four may be 
poisonous to an adult, while eight may be fatal. A fatal ingested dose for human is about $1 \mu \mathrm{g} / \mathrm{kg}$ (Clark 1997). Because the alimentary tract destroys lots of ricin, it is much more potent when administered paraenterally. The toxically active Achain of ricin is a 267 amino acid globular protein and is classed as an $\mathrm{N}$-glycosidase. The A-chain is protein containing 8 alpha helices and 8 beta sheets (Katzin et al. 1991, Morris and Wool 1994). The Bchain is composed of 262 amino acid residues and is classed as a lectin (Katzin 1991). The B chain has an affinity for binding to galactosides (Rutenber and Robertus 1991) and posseses two galactose binding sites that are attracted to galactose containing glycoproteins at the cell surface. The A- and Bchain glycoproteins are linked by a disulfide bond located at residue 259 of the A-chain and residue 4 of the B-chain (Montfort et al. 1987). Ricin is a glycoprotein with carbohydrate side chains in the form of mannose-rich $\mathrm{N}$-linked oligosaccharides and particularly binds to mannose receptors of cells of the reticuloendothelial system. The specific sites with potential for binding of high mannose carbohydrate chains of ricin are at asparagines 10 and 236 of the A-chain, and asparagines 95 and 135 of the B-chain (Rutenber and Robertus 1991).

Previously, it was thought that ricin functioned as a blood-agglutinating protein. This was believed because early preparations of extracts from the castor bean plant did in fact agglutinate red blood cells (Lord et al. 1994). It was later found that these early preparations were actually mixtures of ricin and one of the isoforms of ricin, Ricinus communis agglutinin. Ricinus communis agglutinin was actually responsible for the agglutination of red blood cells, but is not very toxic to mammalian cells. It was found that ricin was the more toxic compound, and that it had a different mode of action (Lord et al. 1994). The toxic effects of ricin are essentially the result of the action of the A-chain, which inactivates the ribosomes of the cell. It is thought that the Bchain serves to bind to galactose-containing and/or mannose-containing structures at the cell surface thus allowing the A-chain to enter the cell (Olsnes and Kozlov 2001). By this way the protein is internalized, meaning that it is taken into the cell as a toxin-binding site complex in vesicles. The Bchain of ricin facilitates the escape of the A-chain by binding to the endosomal membrane allowing the A-chain to pass through the membrane. Then, the Bchain dissociates from the A-chain by breaking the disulfide bond. The A-chain is thus delivered to the cytoplasm where it is taken up by the Golgi apparatus and transported to the endoplasmic reticulum (Olsnes and Kozlov 2001).

At the endoplasmatic reticulum, ricin inactivates the cell ribosomes by elimination of adenine in specific RNA sequences on the $28 \mathrm{~S}$ ribosomal subunit (Lord et al. 1994). A single A-chain molecule is capable of deactivating every ribosome in the cell thus halting protein synthesis and culminating in cell death. It is important to note that the toxin is specific for eukaryotic ribosomes. A hairpin loop on the 28S rRNA containing the tetranucleotide loop GAGA is the most likely target for attack by ricin on the ribosome, however it is thought that the ribosome conformation is an important factor in recognition by the protein (Lord et al. 1994). Therefore, ricin is not a nucleotide sequence-specific protein.

Ricin can be toxic to the ribosomes of $R$. communis itself, therefore the plant has evolved mechanisms to avoid cell suicide. Ricin is synthesized at the ribosome in the endosperm tissue of the seed not as its active, toxic form, but as single chain protein proricin (Frigerlo 1998). Proricin is then transported via the Golgi complex to the vacuoles where it is processed by a vacuolar processing enzyme, endopeptidase. The proricin thus is cleaved into the A- and B-chains which are still held together by a disulfide bond since the cleavage occurs within a disulfide loop that connects the two chains. Endopeptidase cleaves the chains by removing a 12-residue peptide link between the Aand $\mathrm{B}$-chains thus forming the active ricin, which is stored in the vacuole (Lord et al. 1994). Both the Aand B-chains of ricin are coded for by a single mRNA sequence (Montfort et al. 1987).

\begin{abstract}
ABRIN
Abrin is a potent toxin that has been isolated from the seeds of Abrus precatorius (or Rosary pea). Its use as a tool for research was described in 1972 by Sharon and Lis (Sharon and Lis 1972). Abrin exists in two forms, abrin a and abrin b. Both are composed of two chains, an A-chain and a B-chain. A disulfide bond between Cys247 of the A-chain and Cys 8 of the B-chain links the A and B chains. The A-chain is 251 residues and is divided into 3 folding domains. The A-chain catalytically inactivates $60 \mathrm{~S}$ ribosomal subunits by removing adenine from positions 4 and 324 of $28 \mathrm{~S}$ rRNA therefore inhibiting protein synthesis. The B-chain is a galactose specific lectin that facilitates the binding of abrin to cell membranes (Olsnes and Pihl 1976, Chen et al. 1992). The B-chain of both forms of abrin consists of 268 amino acid residues and shares 256 identical residues. Comparison of their sequences with that of the ricin's B-chain shows that $60 \%$ of the residues of abrin's B-chain are identical to those of the ricin's B-chain and that two saccharide-binding sites in ricin B-chain identified
\end{abstract}




\section{Patočka and Středa}

by a crystallographic study are highly conserved in abrin B-chain (Kimura et al. 1993).

The mechanism of toxic action of abrin is identical to that of ricin, but the toxicity of abrin in mice is 75 times higher that of ricin $(0.04 \mu \mathrm{g} / \mathrm{kg}$ for abrin compared to $3 \mu \mathrm{g} / \mathrm{kg}$ for ricin). The diagnosis, clinical features, treatment, protection, prophylaxis and so on is also the same for both abrin and ricin intoxications (Olsnes et al. 1978).

\section{VISCUMIN}

Viscumin (Mistletoe lectin I, ML I), inevitable to the family of RIPs, was identified in the late 1980s as the main pharmacologically-active ingredient of mistletoe (Viscum album) extract and is largely responsible for its toxicity (Krauspenhaar et al. 1999). It is comparable in toxicity to ricin and acts by the same mechanism. When viscumin binds to its target cell, protein synthesis in that cell is interrupted as a result of the A-chain's enzymatic activity, like a ricin. This interruption induces a cellular stress response, which triggers the release of cytokines by the target cell and, at high viscumin concentrations, apoptosis of the cell. Very similar heterodimeric toxic viscumin was isolated from a partial-parasite obtained from Indian western Himalayas. The purified viscumin from this source shows considerable sequence and structural differences with the european viscumin. The root mean-square-deviations (r.m.s) calculated for $\alpha-$ carbon atoms of european ML-1 and Indian viscumin show higher deviations for the A chain and lower for the B chain. The highest deviations are found for the residues on the surface. The association of A- and B-subunits is predominantly hydrophobic in nature.

\section{VOLKENSIN}

Volkensin is a lectin from Adena volkensii (the kilyambiti plant) that is comparable in toxicity to ricin and that acts by the same mechanism (a ribosome-inactivating protein). The plant is a relatively unattractive and toxic succulent plant found in Africa that appears to be of little interest. However, it has proven useful as a research reagent in neurology because of its ability to be taken up and transported by certain types of nerve. There may be pressure to develop commercial sources for the research community.

\section{MODECCIN}

Modeccin is a lectin from the roots of Adenia digitata an African succulent plant that is comparable in toxicity to ricin (Olsnes et al. 1982) and acts by the same mechanism (Refsnes et al. 1977, Olsnes et al. 1978). The plant does not seem to have any significant uses, such as food or medicine and so is not available in quantities comparable to abrin, let alone ricin. However, the seed does seem to be readily available. The subunits were isolated of modeccin (subsequently referred to as modeccin 4B), purified from the roots of Adenia digitata by affinity chromatography on Sepharose 4B (Gasperi-Campani et al. 1978). They are an A subunit (mol.wt. 26 000), which inhibits protein synthesis, and a B subunit (mol.wt. 31 000), which binds to cells. Both subunits, as well as intact modeccin, gave single bands on sodium dodecyl sulphate/polyacrylamide-gel electrophoresis, but showed some heterogenity on isoelectric focusing and on polyacrylamide-gel electrophoresis at $\mathrm{pH} 9.5$. A second form of modeccin, not retained by Sepharose 4B, was purified by affinity chromatography on acid-treated Sepharose 6B: this form is subsequently termed modeccin 6B. Modeccin 6B has a molecular weight indistinguishable from that of modeccin $4 \mathrm{~B}$, and consists of two subunits of mol.wts. 27000 and 31000 , joined by a disulphide bond. The subunits were not isolated because of their high insolubility in the absence of sodium dodecyl sulphate. As compared with modeccin 4B, modeccin $6 \mathrm{~B}$ is slightly less toxic to animals, does not agglutinate erythrocytes, and is a more potent inhibitor of protein synthesis in a lysate of rabbit reticulocytes, giving $50 \%$ inhibition at the concentration of $0.31 \mu \mathrm{g} / \mathrm{ml}$ (Barbieri et al. 1980).

\section{ILLNESS SYMPTOMS AND DEATH}

Illness symptoms of all RIPs and the course of poisoning are very similar because the mechanism of toxic action of these toxic proteins is identical. Best known is poisoning of human by ricin, almost 750 intoxication. Toxic effects of ricin have a latent period and take 2-24 hours to develop. After ingestion the primary symptoms are abdominal pain, vomiting and diarrhoea often with blood. The toxin causes haemorrhages in the intestine, mesenterium and omentum. It may also cause a diffuse nephritis, multiple necroses in the liver and kidneys with cytoplasmic vacuolation and pyknosis of the nuclei (Knight 1979). In the myocardium the myofibrils undergo degeneration. Within several days there is severe dehydration, a decrease in urine, thirst, 
burning throat, headache and the patient may die from hypovolemic shock. The patients' temperature decreases before death, and they often undergo a characteristic shivering. Death occurs in exhaustion or cramp. When administered paraenterally ricin is twice as toxic as cobra venom, and is probably the most toxic paraenteral substance in the plant kingdom. After paraenteral administration the patient may present with fever, leucocytosis, and then falling blood pressure and temperature. The primary target organs are the kidney, liver, and pancreas. Differences in toxicities of particular RIPs are not very distinct. From the literary data the most toxic is abrin (Patocka 2001).

\section{SIGNIFICANCE FOR WARFARE}

Ricin is the only toxin to exist naturally in large quantities. It is a byproduct of castor oil production and ricin isolation is a simple and cheap separation. Easy preparation and low price might make this toxin attractive to a poor country. Abrin may be considered to be an available toxin for weaponizing because its source, Abrus precatorius, may be easily cultivated and the preparation of the pure toxin is not complicated. For nations or terrorists who lack the money to spend on nuclear weapons and other high-tech killing instruments, toxin warfare offers horrific appeal: biological/toxin weapons are cheap, easy to make, and simple to conceal. Even small amounts, if effectively used, could cause massive injuries and make many suffer (Patocka 1998). Ricin's significance as a potential biological warfare toxin relates in part to its wide availability. Worldwide, one million tons of castor beans are processed annually in the production of castor oil and in the waste is five percent ricin by weight. The toxin is also quite stable and extremely toxic by several routes of exposure, including the respiratory route (Patocka 2001).

In biological warfare it is expected that ricin would be released as a toxic cloud. It could also be injected into specific persons as a terrorist or sabotage weapon. Additionally, ricin is easy to produce and is stable. The toxic effects of ricin occur because it kills the cells of the body that it contacts when it is taken into the body. Upon inhaling an adequate amount of ricin, death of persons affected would be expected in 36-48 hours because of difficulty breathing and circulatory system effects. Ingested ricin is expected to cause internal bleeding, death of vital organs and death of the individual. Injected ricin causes death by major organ failure.

The prediction of symptoms to be expected is based on animal studies and accidental human exposures, which were not fatal. Symptoms would probably vary depending on whether ricin was inhaled, ingested or injected. About three hours after inhaling ricin, the symptoms expected are cough, tightness of the chest, difficulty breathing, nausea and muscle aches. This would progress to a severe inflammation of the lungs and airways, increased difficulty breathing, cyanosis and death in 36-48 hours from failure of the breathing and circulatory systems. Ingestion of ricin would be expected to cause nausea and vomiting, internal bleeding of the stomach and intestines, failure of the liver, spleen and kidneys and death of the individual by collapse of the circulatory vessels. No specific affects on the lungs and airways would be expected. If injected, ricin causes marked death of muscles and lymph nodes near the site of injection and probable failure of major organs and death of the individual.

\section{MEDICAL COUNTERMEASURES AND THERAPY}

There is currently no vaccine available to be given before exposure to ricin although vaccines are under development by the U.S. Army. There is no ricin antitoxin to be given after exposure; therefore, the only treatment available involves management of the effects based on the method of exposure to the toxin. If ricin is inhaled, oxygen may be given as well as drugs to reduce inflammation and support the function of the heart and circulatory system. Ingestion of ricin would by treated by emptying the stomach and intestines of their contents and replacing lost fluid. It is not known whether these measures would be life saving. There is no specific treatment for injected ricin other than making the person comfortable and using any measures normally used to treat organ failure. Recovery would not be expected if an adequate dose of ricin were injected. Ricin and other RIPs are not dialyzable. There is no antidote.

\section{PROTECTIVE COUNTERMEASURES}

The usually chemical protective masks are effective against inhaled ricin as well as against all other RIPs. Future protection efforts are aimed at developing a vaccine against inhaled ricin. As a toxin, ricin acts directly on the individual exposed to it and is not reproduced within the individuals: it cannot be passed from person to person. Quarantine of affected individuals would be of no value.

\section{DECONTAMINATION}


Decontamination of contaminated articles may be accomplished using a $0.05 \%$ hypochlorite solution.

\section{POSSIBILITIES OF REAL-TIME DETECTION}

Real-time detection of toxins is very important, because without timely warning, the most effective generic countermeasure of soldiers, the protective mask, may be of limited value. There have been successful efforts in the past to develop real-time detectors of a chemical agent attack. It will be more difficult to develop such detectors for toxins for several reasons. As stated above, toxins must be presented as inspireable aerosols, which act as a cloud, not as vapors or droplets, as the chemical agents. Toxin detectors working at the present state of technology would likely have to have the specificity of immunoassays to identify a toxin and differentiate it from other organic material in the air. Continuous monitoring by such equipment would be extremely costly and logistically very controversial. Analytical assays would necessarily be more complex and less likely to identify distinct toxins, but might detect that something unusual was present. This might be almost possible on a battlefield, but would be nearly impossible in the case of a terrorist attack. We must hope that future advances in technology could well resolve our present technical difficulties.

\section{SIGNIFICANCE FOR MEDICINE}

The capability of RIPs to act as a potent cytotoxin and to block protein synthesis allure physicians to exploit them as possible anti-cancer therapeutics. This idea is not quite new. For example natural extract of mistletoe (Viscum album) is widely used as an alternative complementary cancer therapy, especially in German-speaking countries, but researchers, have been skeptical of its use (Stein et al. 1998). Nevertheless, new investigations and preliminary data from clinical trials suggest that RIPs may be very interesting natural compounds as alternative cancer therapy, likewise the yew treederived cancer therapeutic taxol.

Natural extracts have the disadvantage that they contain many ingredients at varying concentrations. Using recombinant technology in Escherichia coli, Viscum researchers produced a protein with structural similarity to the original viscumin. Animal studies indicate that this recombinant viscumin (rViscumin) has cytotoxic activity against various types of cancer (Schaffrath et al. 2001). The drug is now in several clinical Phase I trials in Europe.
Early results from a dose-escalation study that is underway in Hanover, and in Nantes, France, were presented recently at the EORTC-NCI-AACR Symposium on Molecular Targets and Cancer Therapeutics in Frankfurt. Twenty eight German patients with a solid malignant tumor who received infusions of rViscumin twice a week showed an "ideal pharmacokinetic scenario", reported Schöffski, who is supervising the Hanover trial. The treatment was well tolerated even at high concentrations. rViscumin differs from its natural plant equivalent in that it is expressed in bacterial cells, which do not glycosylate proteins as do plant cells. It is probably very important as well as the fact that rViscumin stimulates the immune system over a broad range of doses with the release of IL-1beta, IL-6, IFN-gamma and TNF-alpha. The recombinant protein also induces $\operatorname{IgG}$ and $\operatorname{IgM}$ antibodies, but the clinical relevance of this finding is not known.

\section{CONCLUSIONS}

Ribosome-inactivating proteins (RIP) abrin, ricin, viscumin, modeccin and volkensin are very potent toxins derived from plants. They are extremely toxic for all warm-blooded animals including human and represent potential biological warfare toxin and easy exploitable means for terroristic attack. Especially ricin for its easy availability is alluded as acute terrorist danger very often lately. On the other hand, RIPs represent interesting tool for cancer therapy. Very promising results have been obtained with recombinant viscumin that may become an alternative therapy to other plant-derived chemotherapy, such as taxol isolated from the bark of the Pacific yew tree (Taxus brevifolia).

Received $7^{\text {th }}$ April 2003.

Published online $11^{\text {th }}$ July 2003.

\section{REFERENCES}

Barbieri L., M. Zamboni, L. Montanaro, S. Sperti, F. Stirpe: Purification and properties of different forms of modeccin, the toxin of Adenia digitata. Separation of subunits with inhibitory and lectin activity. Biochem. J. 185: 203-210, 1980.

Clark, K: The Chemical Weapons Convention: Chemical and Toxin Warfare Agents and Plant Toxic Proteins and their Significance Disarmament. Royal Military College of Science, Cranfield University, August 1997. 
Endo Y., T. Oka, K. Tsurugi, H.Franz: The mechanism of action of the cytotoxic lectin from Phoradendron californicum: the RNA Nglycosidase activity of the protein. FEBS Lett. 248: 115-118, 1989.

Gasperi-Campani A., L. Barbieri, E. Lorenzoni, L. Montanaro, S. Sperti, E. Bonetti: Modeccin, the toxin of Adenia digitata. Purification, toxicity and inhibition of protein synthesis in vitro. Biochem. J. 174: 491-496, 1978.

Chen Y.L., L.P. Chow, A. Tsugita, J.Y. Lin: The complete primary structure of abrin-a B chain. FEBS Lett. 309: 115-118, 1992.

Katzin B.J., E.J. Collins, J.D. Robertus: Structure of ricin A-chain at 2.5 A. Proteins 10: 251-259, 1991.

Kimura M., T. Sumizawa, G. Funatsu: The complete amino acid sequences of the B-chains of abrin-a and abrin-b, toxic proteins from the seeds of Abrus precatorius. Biosci. Biotechnol. Biochem. 57: 166-169, 1993.

Knight B.: Ricin - a potent homicidal poison. Br. Med. J. 1 (6159): 350-351, 1979.

Krauspenhaar R., S. Eschenburg, M. Perbandt, V. Kornilov, N. Konareva, I. Mikailova, S. Stoeva, R. Wacker, T. Maier, T. Singh, A. Mikhailov, W. Voelter, C. Betzel: Crystal structure of mistletoe lectin I from Viscum album. Biochem. Biophys. Res. Commun. 257: 418-424, 1999.

Larsson S.L., M.S. Sloma, O. Nygard O: Conformational changes in the structure of domains II and V of 28S rRNA in ribosomes treated with the translational inhibitors ricin or alpha-sarcin. Biochem. Biophys. Acta 1577: 53622002.

Lord J.M., L.M. Roberts, J.D. Robertus: Ricin: structure, mode of action, and some current applications. FASEB J. 8: 201-208, 1994.

Manske J.M., D.J. Buchsbaum, D.A. Vallera: The role of ricin $B$ chain in the intracellular trafficking of anti-CD5 immunotoxins. J. Immunol. 142: 1755-1766, 1989.

Montfort W., J.E. Villafranca, A.F. Monzingo, S.R. Ernst, B. Katzin, E. Rutenber, N.H. Xuong, R. Hamlin, J.D. Robertus: The three-dimensional structure of ricin at 2.8 A. J. Biol. Chem. 262: 5398-5403, 1987.
Morris K.N., I.G. Wool: Analysis of the contribution of an amphiphilic alpha-helix to the structure and to the function of ricin A chain. Proc. Natl. Acad. Sci. USA 91: 7530-7533, 1994.

Olsnes S. and A. Pihl: Kinetics of binding of the toxic lectins abrin and ricin to surface receptors of human cells. J. Biol. Chem. 251: 3977-3984, 1976.

Olsnes S. and J.V. Kozlov: Ricin. Toxicon 39:1723-1728, 2001.

Olsnes S., K. Sandvig, K. Eiklid, A. Pihl: Properties and action mechanism of the toxic lectin modeccin: interaction with cell lines resistant to modeccin, abrin, and ricin. J. Supramol. Struct. 9: 15-25, 1978.

Olsnes S., K. Refsnes, A. Pihl: Mechanism of action of the toxic lectins abrin and ricin. Nature 249: 627-631, 1974.

Olsnes S., T. Haylett, K. Sandvig: The toxic lectin modeccin. Methods Enzymol. 83: 357-362, 1982.

Patocka J.: Abrin and ricin - two dangerous poisonous proteins. ASA Newsletter 85: 205208, 2001.

Patocka J.: Toxicological characteristic of ricin (in Czech). Voj. Zdrav. Listy 67: 166-168, 1998.

Refsnes, K., T. Haylett, K. Sandvig, S. Olsnes: Modeccin - a plant toxin inhibiting protein synthesis. Biochem. Biophys. Res. Commun. 79: 1176-1183, 1977.

Rutenber E., J.D. Robertus: Structure of ricin Bchain at 2.5 A resolution. Proteins 10: 260-269, 1991.

Sandvig K. and S. Olsnes: Entry of the toxic proteins abrin, modeccin, ricin and diphtheria toxin into cells. I. Requirement for calcium. J. Biol. Chem. 257: 7495-7503, 1982.

Sharon N. and H. Lis: Cell-agglutinating and sugarspecific proteins. Science 177: 949-959, 1972.

Sundan A., K. Sandvig, S. Olsnes: Preparation and properties of a hybrid toxin of modeccin A-chain and ricin B-chain. Biochim. Biophys. Acta 761: 296-302, 1983.

Wang K.Y., Q. Xu: Lectins and Toxins. Sheng Wu Hua Xue Yu Sheng Wu Wu Li Xue Bao (Shanghai) 32: 201-205, 2000.

\section{* Address:}

Jiří Patočka, Katedra toxikologie, Vojenská lékařská akademie, Třebešská 1575, 50001 Hradec Králové, Czech Republic; patocka@pmfhk.cz 